\title{
FROM REALITY TO POINT CLOUDS. SURVEY AND ANALYSIS OF SANT MIQUEL CHURCH OF BATEA (SPAIN).
}

\author{
A. COSTA-JOVER*, D. MORENO GARCÍA*, S. COLL-PLA* AND J. LLUIS I GINOVART ${ }^{\dagger}$ \\ * Escola Tècnica Superior d'Arquitectura \\ Universitat Rovira i Virgili \\ Campus Bellissens, 43204 Reus, Spain

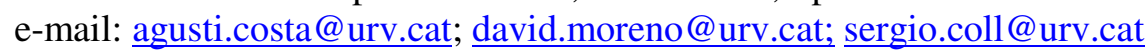 \\ $\dagger$ School of Architecture \\ Universitat Internacional de Catalunya \\ C/ Immaculada, 22, 08017 Barcelona, Spain \\ e-mail: jlluis@uic.es
}

Keywords: Historical Structure, Masonry, Terrestrial Laser Scanner, Non-Destructive Inspection, St. Miquel of Batea Church

\begin{abstract}
Current massive data capture techniques (MDCT), such as terrestrial laser scanning and digital photogrammetry, have become widespread during the last decade, and raises the possibility of developing new assessment methodologies based on the $3 D$ documentation. The paper exposes de results of using simple, non-invasive procedures for the assessment of the shape of a masonry building from a point clouds registered with a terrestrial laser scanner. The case study selected is the church of Sant Miquel of Batea (eighteenth century), located in the province of Tarragona (Spain). The methodology used combines $2 D$ and $3 D$ processes for assessment of the geometry. The results of the investigation have confirmed the good condition of the building. It presents dimensional variations, most of which can be related to the construction process, while some displacements identified provide information about the accommodation process of the masonry structure.
\end{abstract}

\section{INTRODUCTION}

Current architectural heritage documentation procedures are very varied, and the use of massive data capture techniques (MDCT), such as terrestrial laser scanning and digital photogrammetry, have become widespread during the last two decades. These raises the possibility of developing new assessment methodologies based on the 3D documentation [1] [2]. Numerous investigations have tested the techniques' reliability [3], [4] and proved their effectiveness and compatibility to obtain high precision topographical documentation in architectural heritage [5], [6].

The paper exposes de results of using simple, non-invasive procedures for the assessment of the shape of a masonry building from a point cloud registered with a terrestrial laser scanner. The case study selected is the church of Sant Miquel of Batea (eighteenth century) (Figure 1), 
which is located in the province of Tarragona (Spain) [7]. It is one of the most relevant Baroque constructions in Catalunya, due both for their architectural features and decorative elements. The building mainly consists on a basilica ground plan with a transept with a central dome over a ciborium, and a presbytery, where the altar is located. The main body has square columns and three naves, located at almost the same height defining an interior space of hall church (hallenkirchen). In addition, it is remarkable its great measures, of $48.20 \mathrm{~m} \times 26.11 \mathrm{~m}$ in the ground plan, and $19.95 \mathrm{~m}$ in height, measured in the top of the roof of the central nave.

The methodology used combines 2D a 3D processes for the assessment of the geometry, and takes as reference previous works such as [8], [9], [10]. 2D analysis is mainly based on cross sections, which allows to quantify main measures of all structural elements in detail. 3D analysis is based on the comparison with reference shapes, which allows a quantitative and qualitative comparative analysis of spatial elements such as the vaults and the dome.

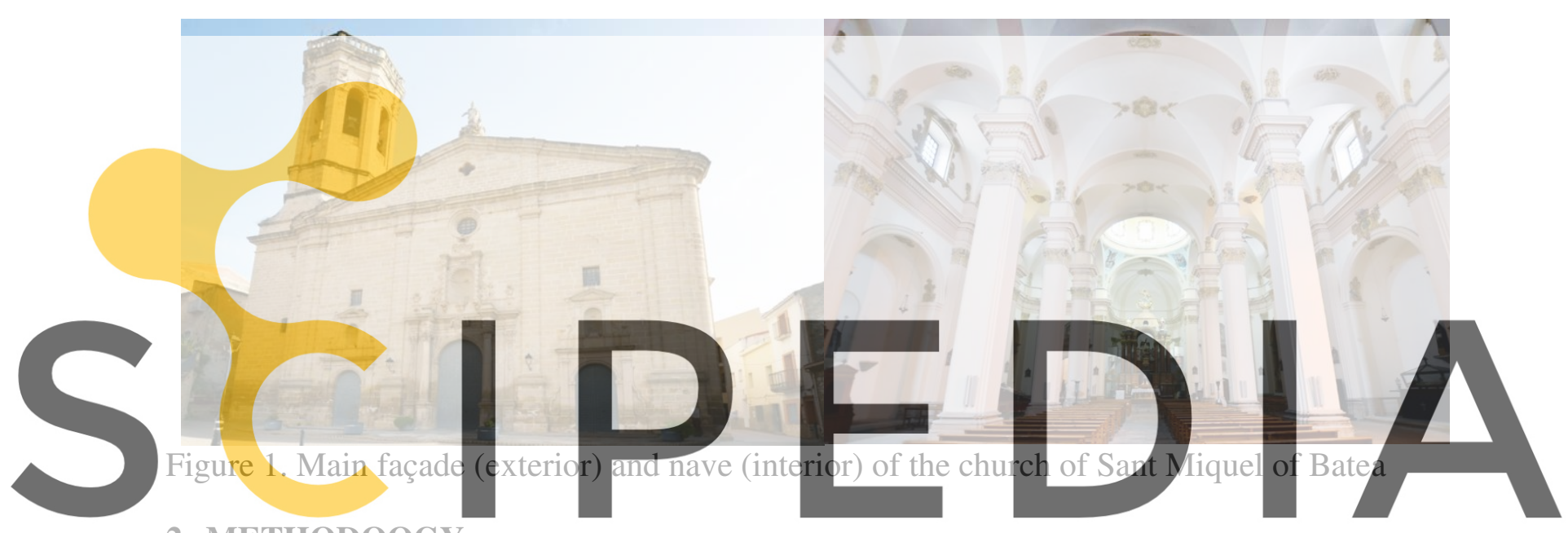

2 METHODOOGY

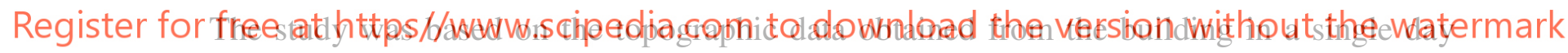

(Campaign: J. Lluis i Ginovart, A. Costa-Jover, S. Coll-Pla) with a Leica laser device, as other

methods were considered not cost-effective, in terms of time and resources, in obtaining the needed accuracy. Despite the survey involved all the building, the assessment was focused on the naves and the central dome.

The device used was a Leica ScanStation C10, with a position accuracy of $6 \mathrm{~mm}$ at $50 \mathrm{~m}$. The architectural layout complexity required a large number of stations to avoid occlusions in the model. The spatial resolution of the scans was set to $1 \mathrm{~cm}$ at $10 \mathrm{~m}$ and the maximum length of the measurements were below $50 \mathrm{~m}$. The coordinates $(\mathrm{x}, \mathrm{y}, \mathrm{z})$ of each point were complemented with RGB information through the photographs taken with the incorporated camera of the device, with a resolution of 1920 x 1920 pixels (4 mp).

The software Cyclone was used to register the point clouds in the same local coordinate system with a standard deviation of $3 \mathrm{~mm}$. The error considered was the result of the target based registration and the accuracy of the device. No resampling of the final point cloud was performed. Thus, the maximum error of the registration process was $9 \mathrm{~mm}$, which was considered to be adequate for the assessment. The density of the obtained point cloud was more than 169 million points. 
After, 3DReshaper was used to generate the 3D mesh of the model from the selected points. The mesh density was adjusted at an average triangle size of $2.5 \mathrm{~cm}$, which was later refined using the same program to avoid aberrations due to point cloud noise.

Once the complete point cloud was obtained, the proposed methodology for the assessment of the building combined 2D and 3D processes. This allowed to adapt the processes according to the construction elements, optimizing the study. The analysis focused on the inside of the construction.

Prior to the assessment, all the fundamental construction elements were discretized. These are: pillars and pilasters $(\mathrm{Pi})$ arches $(\mathrm{Ai})$, vaults $(\mathrm{Vi})$ and finally the central dome. Following, the main parameters to be registered are established, and the corresponding $2 \mathrm{D}$ or $3 \mathrm{D}$ process to obtain them. Despite being a Baroque building, the decoration is not very ornate, so there are no excessive areas where registration of measures is difficult.

The 2D study was based on the thorough sectioning of the construction elements. Figure 2 summarizes de nomenclature used for every element and section. Cross sections were made for each element, according to the main axes (i.e. cross sections from the longitudinal and transversal axes of the nave) that define the main points of the geometry of the elements assessed. Following, the study compared the differences between equal points between elements to identify possible movements.
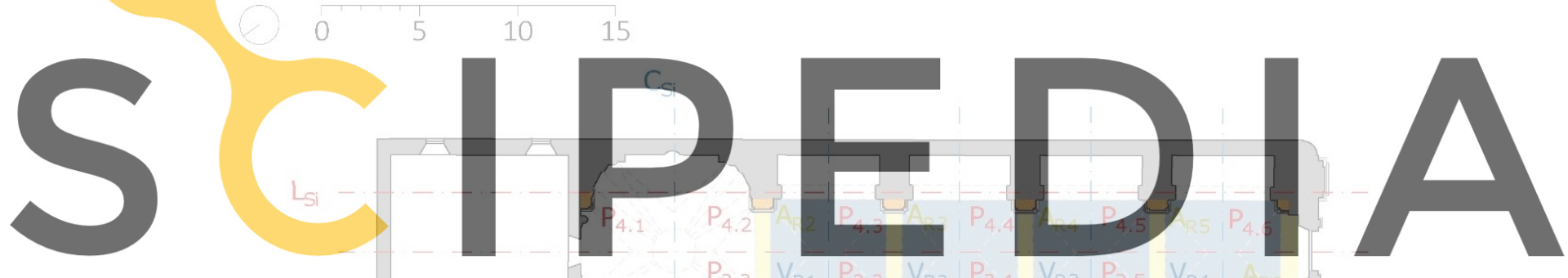

Register for free at https//www.scipedia.com to download the version without the watermark

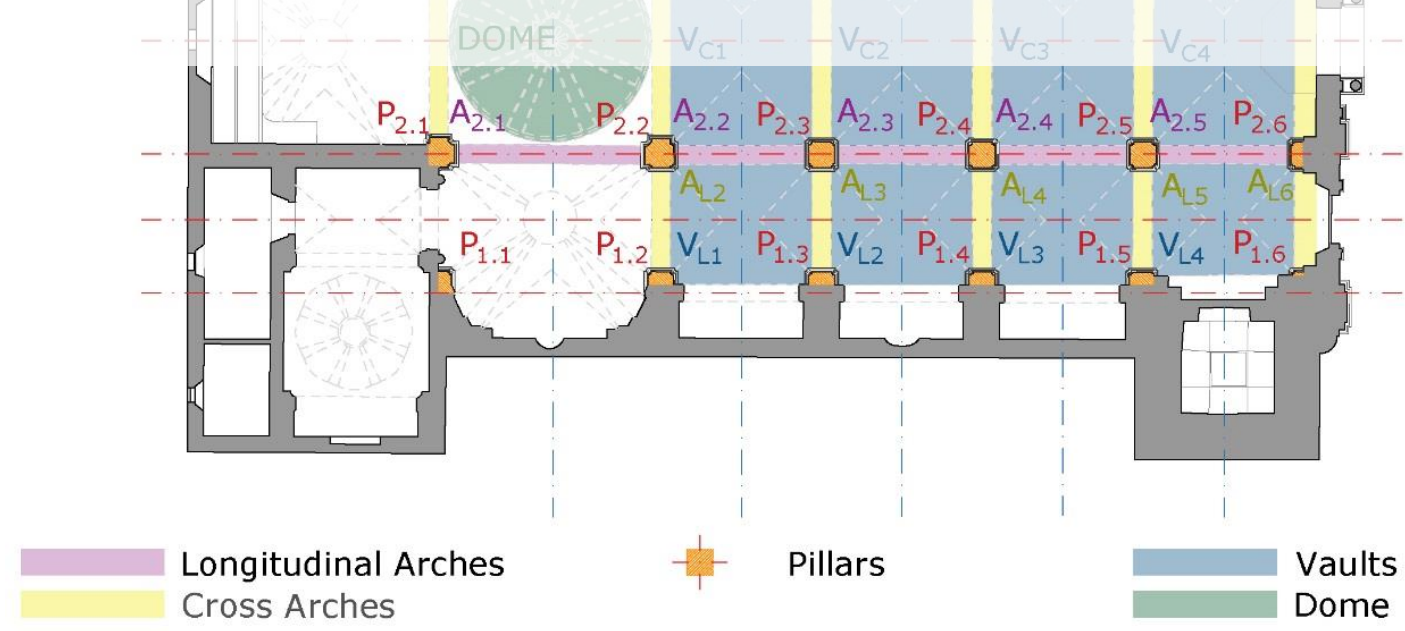

Figure 2. Elements assessed and nomenclature.

The 3D assessment was performed with the program 3DReshaper. This software allowed to 
obtain the range of distances (point to surface) between a point cloud and a shape of reference. The study in that case focused on the vaults and the dome, which shape can only be fully understood in 3D. Two variants of the assessment were performed. First, the shape of the vaults was analysed compared to a horizontal reference plane. A different height from the reference plane was established for the side aisles and the central vault. This approach allowed to identify differences between the vaults simply and quickly. Complementarily, contour lines spaced every $10 \mathrm{~cm}$ were defined from the vaults mesh, to define a topography of the elements. Second, the central nave and the dome were assessed according to a primitive shape of comparison, a cylinder and a sphere correspondingly. These two analysis allowed to identify differences between equal elements, which at first glance may not be appreciated. The formal anomalies can be related to deviations during construction, or to movements of the structure after construction.

\section{RESUITS}

\subsection{D Assessment}

The exhaustive sectioning allows a first and easy approximation of the formal alterations that the structural elements may have suffered. In this case, pillars and pilasters (Pi) arches (Ai) and vaults (Vi).
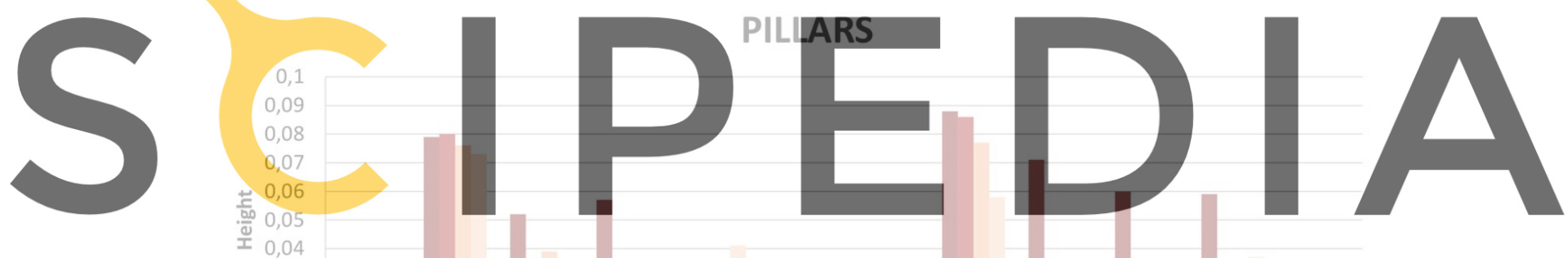

Register for free ąt https//www.scipedia.com to download the version without the watermark

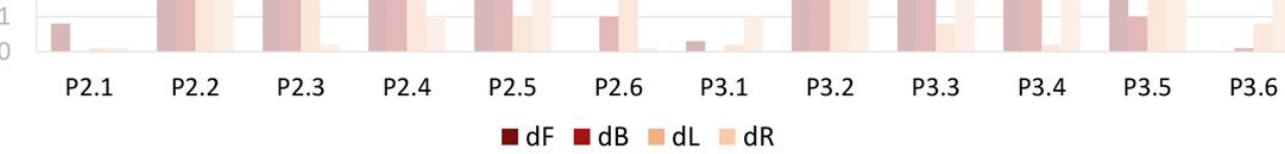

\section{PILASTERS}

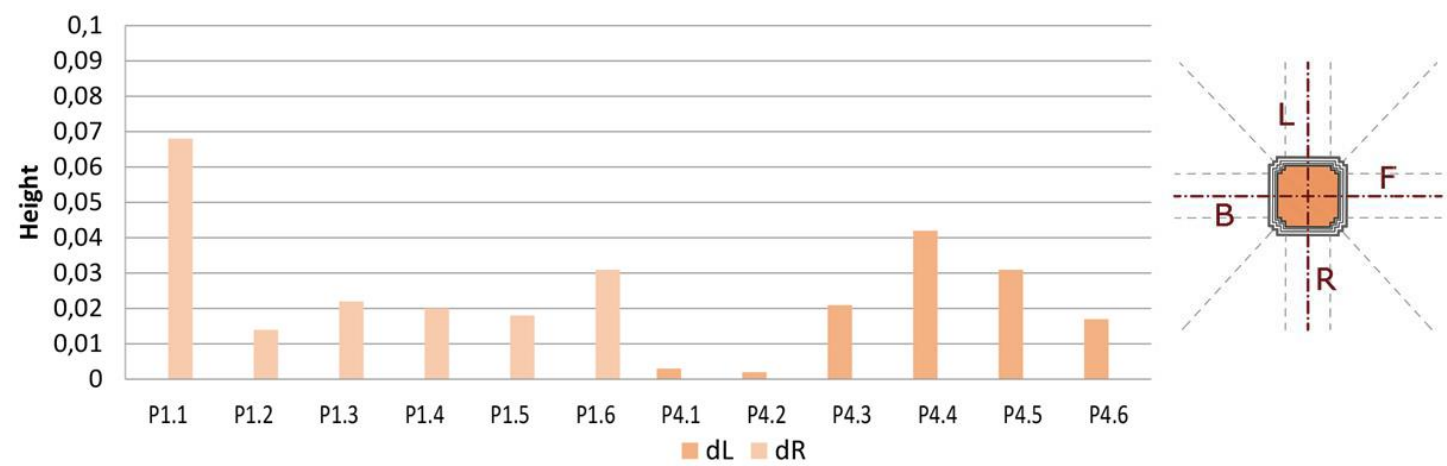

Figure 3. Values obtained in central pillars and pilasters (up) and lateral pilasters (bottom). 
For the study of the pillars and pilasters the possible out of plumb points have been analysed, based on the displacements on the axis (x), measured in the upper end of the capital moulding and the lower end of the base of each column. The column shaft line was projected to the base and capital mouldings ends so as not to distort the measurement. Each pillar was measured on both sides of each axis, obtaining the measurements $(\mathrm{dF}, \mathrm{dB})$ through longitudinal sections (Ls), and $(\mathrm{dL}, \mathrm{dR})$ in the cross sections $\left(\mathrm{C}_{\mathrm{S}}\right)$. In the case of pilasters, it was not possible to register all the coordinates, given the existence of mouldings that distorted an accurate reading at some points.

Figure 3 summarizes the measures obtained, according to the elements located in the central nave (pillars and pilasters) and in lateral walls (pilasters). It can be observed that in general terms, the values of the displacements are low. In the case of pillars, the range of displacements (x) in the longitudinal direction $\left(\mathrm{Ls}_{\mathrm{S}}\right)$ is $[\mathrm{P} 3.2 \mathrm{dF}: 0.088 \mathrm{~m}-\mathrm{P} 3.6 \mathrm{~dB}: 0.001 \mathrm{~m}]$. In the transverse direction $\left(\mathrm{C}_{\mathrm{S}}\right)$, the range of values is [P3.2 $\mathrm{dL}: 0.077 \mathrm{~m}-\mathrm{P} 2.1 \mathrm{~d}_{\mathrm{L}}-\mathrm{d}_{\mathrm{R}}: 0.001 \mathrm{~m}$ ]. On the other hand, the values in lateral pilasters tend to be lower. The range of values in $C_{S}$ is $\left[P 1.1_{d R}: 0.068 m\right.$ P4.2dL: $0.002 \mathrm{~m}$ ]. These values are very low, and can be considered invaluable on an architectural scale.

As for the rounded arches between the vaults, the spring line is measured to be over $1.35 \mathrm{~m}$ from the impost of each column. The arches located in the longitudinal direction have a radius of about $2.80 \mathrm{~m}$, and the transverse ones $2.10 \mathrm{~m}$. The measurement of the springing line presents difficulties due to the mouldings, so that only the height of the key was registered. The arches of the collateral chapds were correct reading due to $m$ direction $(\mathrm{Ls})$, the rang direction $\left(\mathrm{C}_{\mathrm{S}}\right)$ of height $16.25 \mathrm{~m}]$ for central arch observed.

Register for free at https//www.scipedia.com to download the version without the watermark
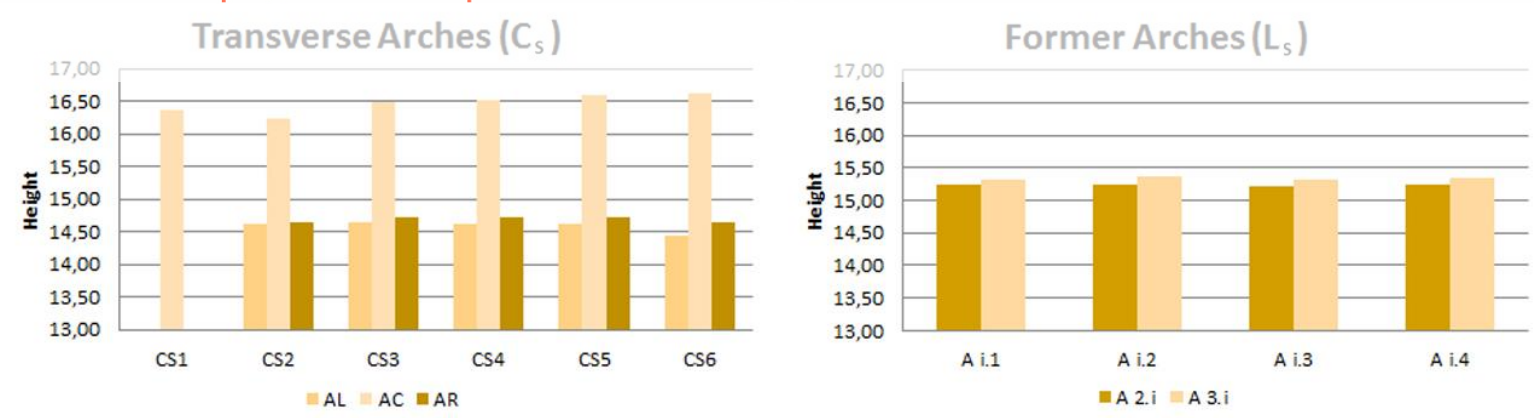

Figure 4. Values obtained in the arches keystones. Transverse arches $\left(\mathrm{C}_{\mathrm{S}}\right)$, Former arches $\left(\mathrm{L}_{\mathrm{S}}\right)$

Finally, the 2D study of the vaults is made from the registration of the points located on the axial axes (longitudinal LS, transverse $\mathrm{C}_{\mathrm{S}}$ ) that determine their geometry. The (y) of selected points are registered, based on a common horizontal reference plane, which is located at the average height of the pavement of all the sections. Figure 5 shows the values obtained in the vaults located on the left $\left(\mathrm{V}_{\mathrm{L}}\right)$ and on the right $\left(\mathrm{V}_{\mathrm{R}}\right)$ of the central nave, and the vaults of the latter $\left(\mathrm{V}_{\mathrm{C}}\right)$. The extreme values in the collateral vaults are $\left(\mathrm{V}_{\mathrm{R} 2}: 15,542 \mathrm{~m}-\mathrm{V}_{\mathrm{R} 4}: 14,616 \mathrm{~m}\right)$, and 
in the central vault $\left(\mathrm{V}_{\mathrm{C} 4}: 16,741 \mathrm{~m}-\mathrm{V}_{\mathrm{C} 2}: 15,309 \mathrm{~m}\right)$. The maximum difference between comparable points (i.e., same point in analogous vaults) is $0.268 \mathrm{~m}$ between points of $\mathrm{V}_{\mathrm{L} 4}$ and $\mathrm{V}_{\mathrm{R} 4}$ of collateral vaults, and $0.165 \mathrm{~m}$ between points $\mathrm{V}_{\mathrm{C} 1}$ and $\mathrm{V}_{\mathrm{C} 4}$ of central vaults.
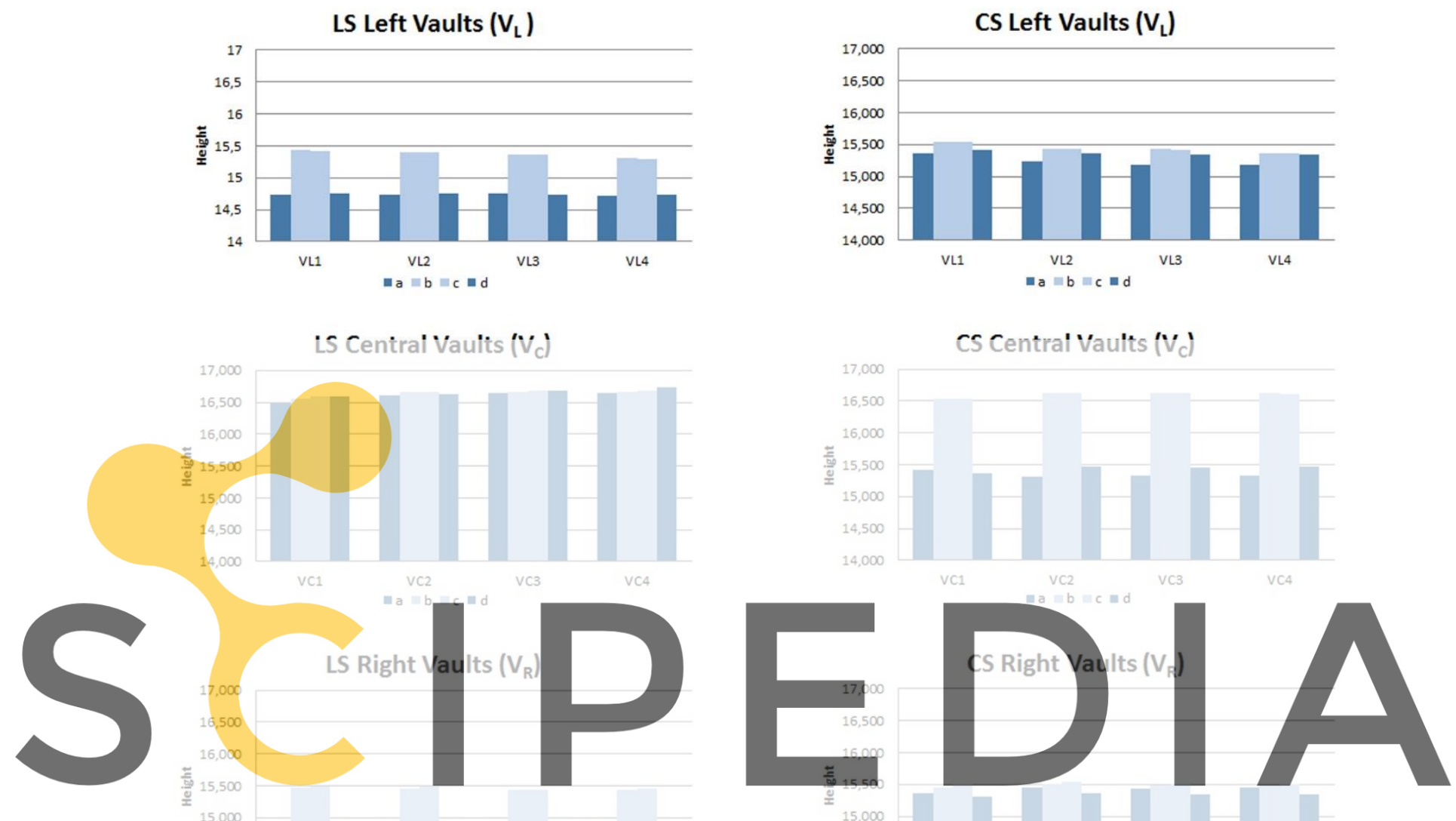

Register for free at https//www.scipedia.com to download the version without the watermark
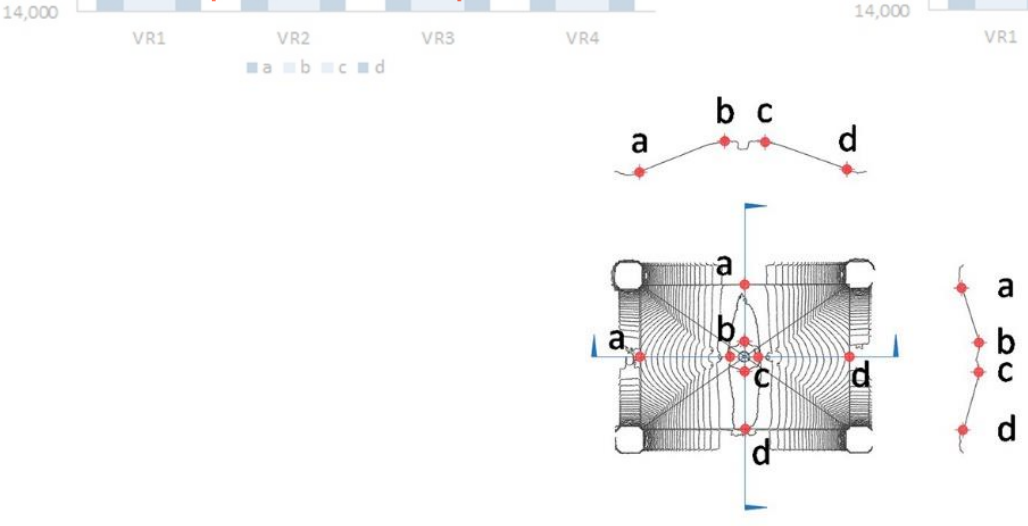

Figure 5. Values obtained in vaults for Left side aisle $\left(\mathrm{V}_{\mathrm{L}}\right)$, Right side aisle $\left(\mathrm{V}_{\mathrm{R}}\right)$ and the central nave $\left(\mathrm{V}_{\mathrm{C}}\right)$, according to axial axis $\left(\mathrm{LS}_{\mathrm{i}}\right)$ and $\left(\mathrm{CS}_{\mathrm{i}}\right)$. 


\subsection{D Assessment}

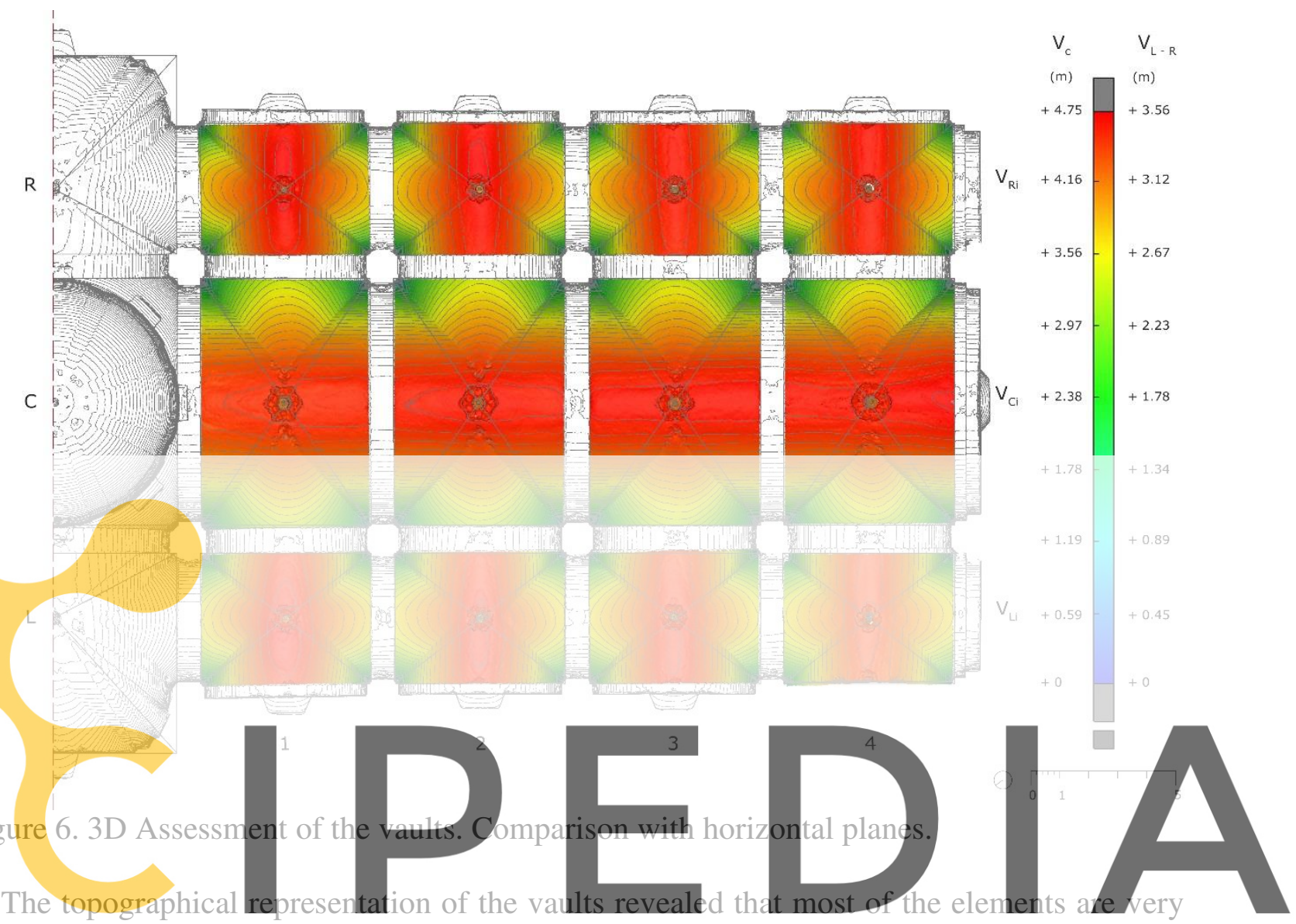

similar, since no relevant differences can be seen. The visualization includes the maps of the

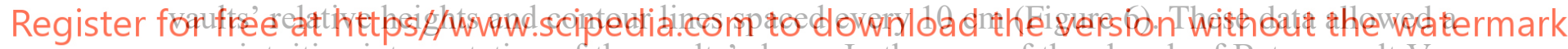

very intuitive interpretation of the vaults' shape. In the case of the church of Batea, vault VL4

has the most relevant differential gradient with respect to the rest of the rest of vaults. This is

consistent with the results obtained in the 2D study. On the other hand, Figure 7 compares the distance distributions for each vault showed in Figure $6\left(V_{C}, V_{L} \& V_{R}\right)$. The ranges measured are mainly at a distance from the reference plane between $3.56 \mathrm{~m}-3.12 \mathrm{~m}$, and $2.67 \mathrm{~m}-3.12$ $\mathrm{m}$, which represent the $69.6 \%$ of the points.

Regarding the assessment from primitives, the data of the elements of comparison are summarized in Table 1. The central nave has been analysed in comparison with the cylinder that best suits the geometry of the barrel vault part (Figure 8). The results show how central sections are which best fits the ideal cylinder, while the vault section near the dome is the least. As for the dome, it is compared with a sphere. A differentiation is made between the fundamental parts, nerves and shell, and a sphere is defined for each one (Figure 9). The study reveals a certain settlement of the upper part of the dome, due to the weight of the lantern. This deformation is not uniform, and the most settled area can be related with a deformation at medium height in the opposite quarter of the dome. It is remarkable that ribs did not reproduce the same differences regarding the shell. 
A. Costa Jover, D. Moreno García, S. Coll Pla, J. Lluis i Ginovart
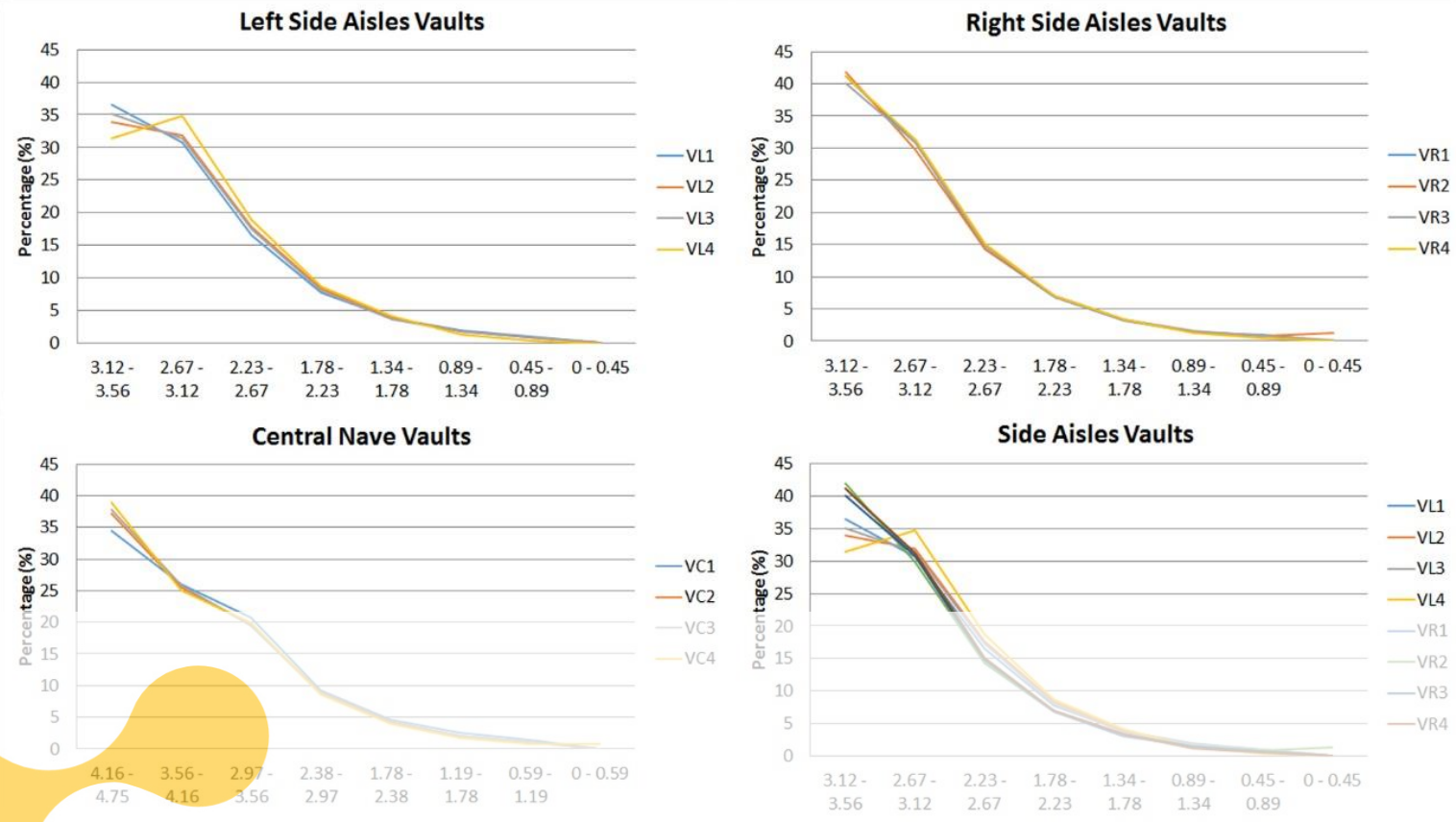

Figure 7. 3D vaults assessment. Graphics of ranges comparison.
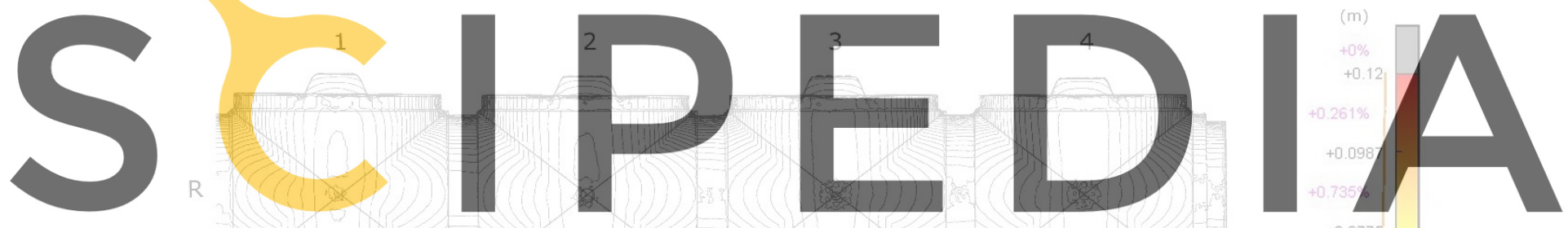

Register for free at https//www.scipedia.com to download the version without the watermark

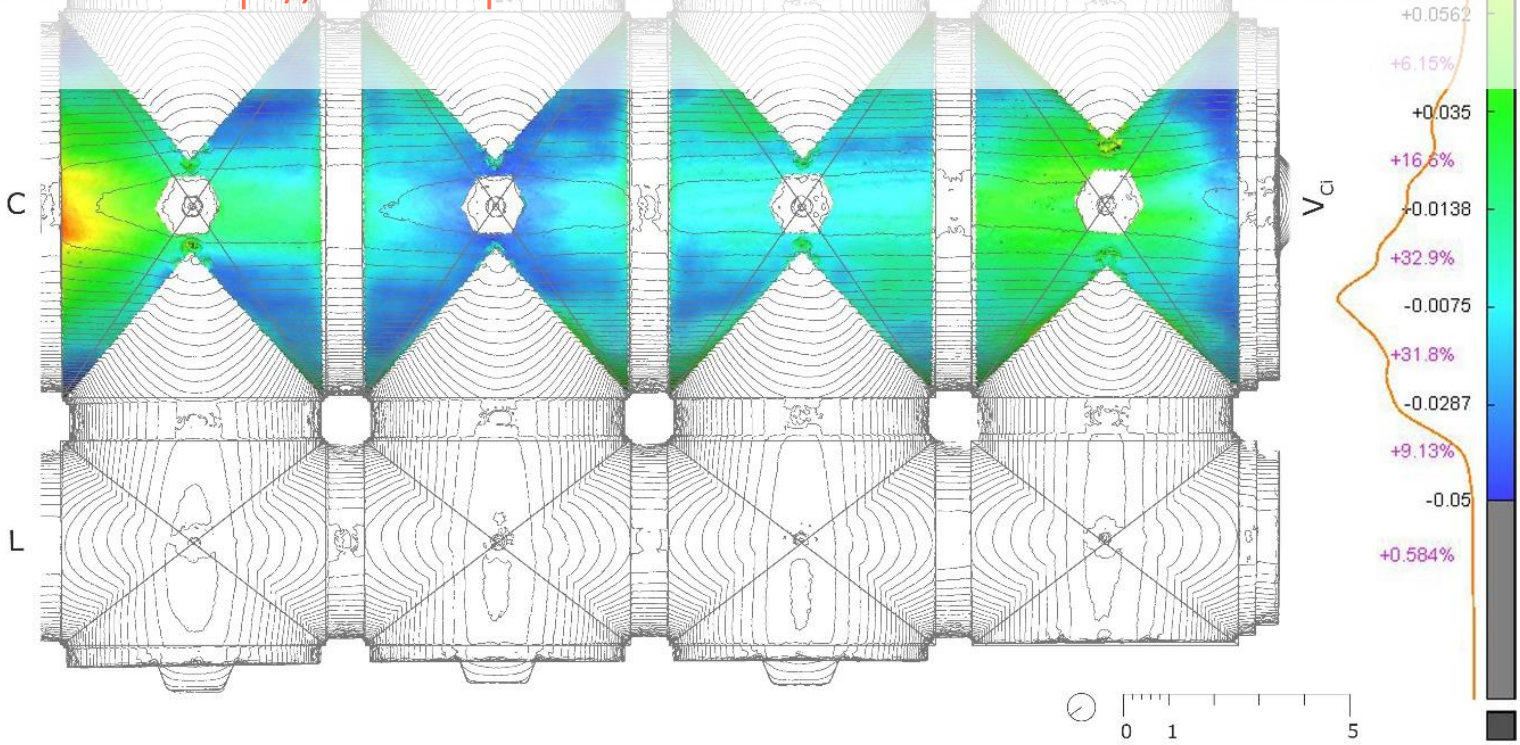

Figure $8.3 \mathrm{D}$ assessment of the central vault from standard primitives. 

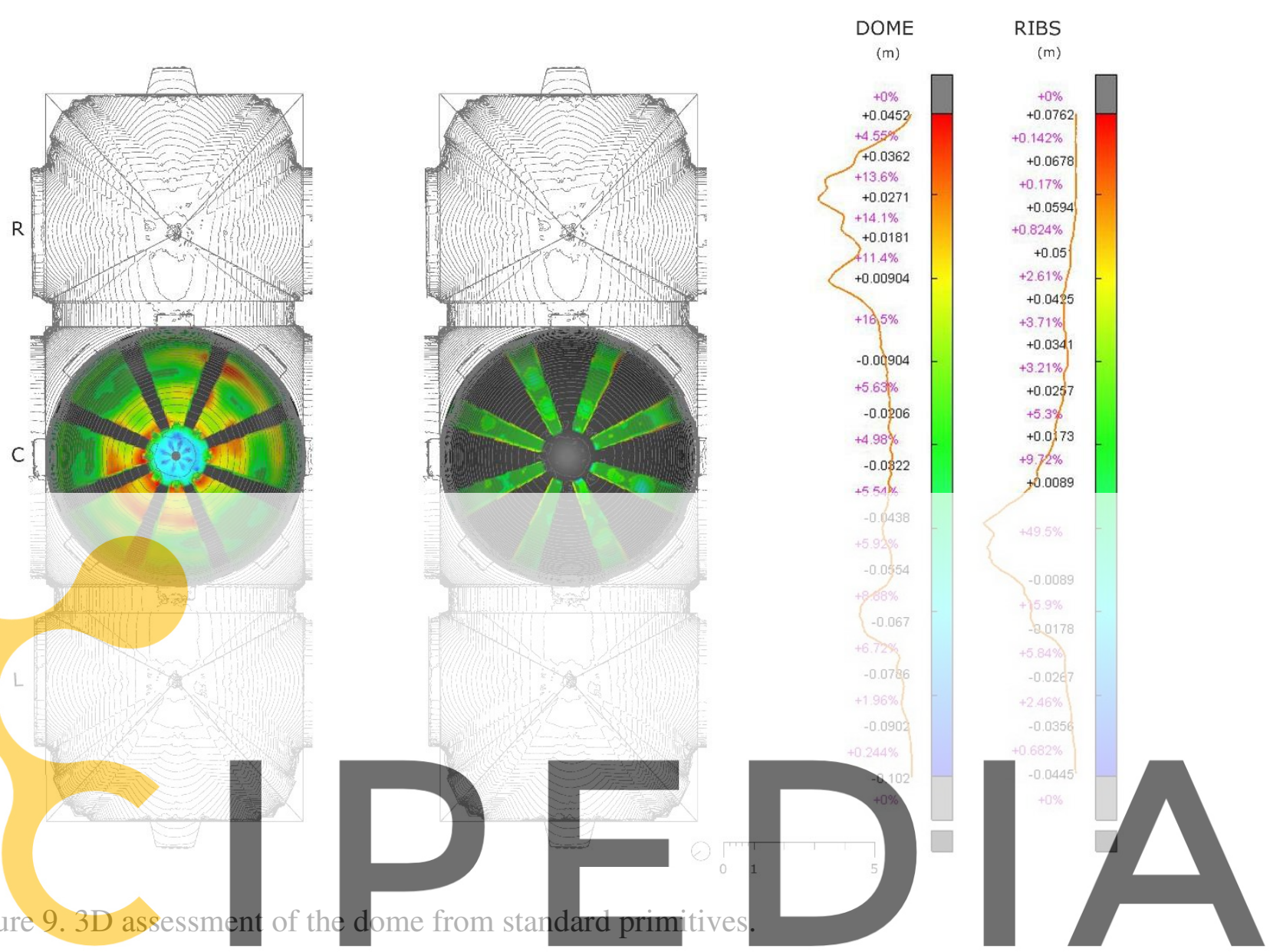

Figure 9.3D assessment of the dome from standard primi

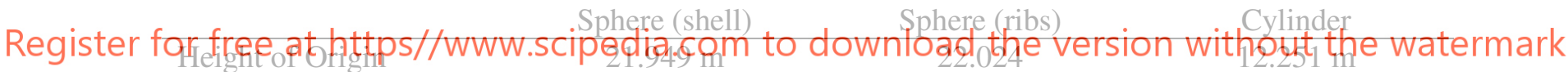

\section{Radius}

Area

Volume

Length
$4.680 \mathrm{~m}$

$239.796 \mathrm{~m}^{2}$

$349.169 \mathrm{~m}^{3}$
$4.270 \mathrm{~m}$

$229.511 \mathrm{~m}^{2}$

$326.180 \mathrm{~m}^{3}$
$4.243 \mathrm{~m}$

$692.616 \mathrm{~m}^{2}$

$25.962 \mathrm{~m}$

Table 1. Main data of primitive forms of comparison.

\section{DISCUSSION}

The methodology used has allowed to parameterize the formal differences between the construction elements of the church of San Miquel of Batea. In general terms, no relevant discrepancies were identified, so the structure has hardly suffered formal alterations. The identified deviations usually have small values, with some exceptions, as in the case of some points of the vaults. Nevertheless, taking into account the size of the building, most of them have no impact on its state of conservation, although there are some trends that should be noted.

Cutting planes has revealed that the leaning of the pillars does not have the same value in parallel faces. There may be a certain execution error, but it is striking that systematically the highest values in the longitudinal sections $\left(\mathrm{L}_{S}\right)$ are produced towards the main facade, while in 
the cross sections they tend to be higher on the face closest to the perimeter walls No differential movements have been observed in (y) between parallel faces. The average value of the displacements in $(\mathrm{x})$ is $0.034 \mathrm{~m}$, finding those of greater magnitude in $\mathrm{P} 2.2_{\mathrm{dB}}: 0,08 \mathrm{~m}$ ) and (P3.2 $\mathrm{dF}_{\mathrm{f}}$ 0,088 $\mathrm{m}$ ), which are caused by the action of the dome.

It is also noteworthy that the displacements of the pillars in the longitudinal direction $\left(\mathrm{L}_{S}\right)$ tend to decrease from the dome to the main facade, while in the transverse direction $\left(\mathrm{C}_{\mathrm{S}}\right)$ they tend to increase, although with much smaller magnitudes. These values have no correspondence in the lateral pilasters, which have an average value of $0.025 \mathrm{~m}$.

Regarding the arches, it can be seen that those located on the east side $\left(\mathrm{A}_{\mathrm{L}}\right)$ are significantly lower than the analogs on the opposite side $\left(A_{R}\right)$, with an average difference of $0.110 \mathrm{~m}$. On the other hand, the height difference between the arches $\left(A_{L}\right)$ is $0.030 \mathrm{~m}$, with the exception of AL6, which is $0.190 \mathrm{~m}$ lower than the others. In the case of arches $\left(A_{R}\right)$, all maintain a maximum difference of $0.080 \mathrm{~m}$. Finally, the central arches $\left(\mathrm{A}_{\mathrm{C}}\right)$ tend to increase their height from the dome to the main facade, with a maximum height difference of $0.380 \mathrm{~m}$ between them.

As for the vaults, the graphs show that in the side aisles, the transverse axis of the vaults tends to be horizontal, while the longitudinal one is pointed towards the key. This situation is reversed in the case of the central vaults. Thus the inclination of the axial axes of the vaults is related to the dimensions of the rectangle of the ground plane, and the inclined axis is the largest. The 3D study has shown a great similarity between analogous elements, although some alterations have also been identified, such as the vault $V_{L 4}$ and $V_{C 1}$, which have a height significantly lower than their peers. In addition, it can be seen that the Lef Vaults $\left(V_{L}\right)$ are noticeably lower than Right ones $\left(V_{R}\right)$. Finally, it is observed that central rault $\left(V_{C}\right)$ tends to be
progressively higher from the dome to the façade.
Moreover, the study of the dome reveals a certain settlement of the upper part, due to the
weight of the lantern. This deformation is not uniform, and the most seted area can be related
with a deformation at medium height in the opposite quarter of the dome. It is remarkable that ribs did not reproduce the same differences regarding the shell. In any case, the values remain

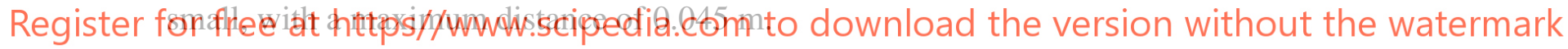

\section{CONCLUSIONS}

The use of massive data capture techniques such as Terrestrial Laser Scanner not only provides accurate geometrical information, but also valuable data about its structural state. The study has proposed a systematization of 2D and 3D operations to analyse a case study, based on a point cloud. Thus, it is possible to identify formal alterations that would otherwise be impossible to determine, and which can have an impact on the conservation of the building.

In the case of the church of San Miquel of Batea, the study has given quantitative and qualitative data about the formal anomalies of the construction elements. Most of that anomalies are no related with degradation processes, since there are no cracks or other related movements. For example, the lower height of the Left Aisle $\left(\mathrm{V}_{\mathrm{Li}}\right)$ regarding the opposites $\left(\mathrm{V}_{\mathrm{Ri}}\right)$ may be related to errors during the construction process, since no relevant movements in the supporting system have been identified, nor settlements in the pavement that can be related with that fact. Otherwise, other movements, such as the ones identified in pillars and pilasters, can be related with the settlement of the building, either during or after construction.

The methodology used can be easily exported to other buildings, and in fact it is easy to find 
many examples of formal studies based on point clouds. Otherwise, it is always necessary to adapt to each specific case, since the characteristics of the buildings, such as size, decoration or complexity among others, conditions the data that can be analysed.

Further research should add the analysis of the exterior of the building and the extrados of the vaults. In addition, the numerical analysis of the structure should reach some light over the displacements identified. Finally, the study of the architectonic rules and possible influences, together with the historiography of the building and its context, would complete the understanding of the construction features.

Acknowledgements. The authors kindly want to thank Mn. Josep Alanyà, who facilitated access to the building under study and shared his wide knowledge. To Ana Maria Solís and Anna Saballs, who collaborated in the initial treatment of the study data.

\section{REFERENCES}

[1] M. Korumaz et al., "An integrated Terrestrial Laser Scanner (TLS), Deviation Analysis (DA) and Finite Element (FE) approach for health assessment of historical structures. A minaret case study," Eng. Struct., vol. 153, no. October, pp. 224-238, 2017.

[2] L. J. Sánchez-Aparicio, A. Villarino, J. García-Gago, and D. González-Aguilera, "Noncontact photogrammetric methodology to evaluate the structural health of historical constructions," Int. Arch. Photogramm. Remote Sens. andSpatial Inf. Sci., vol. 40, no. 5W4, pp. 331-338, 2015.

[3] R. Kadobayashi, N. Kochi, H. Otani, and R. Furukawa, "Comparison and evaluation of laser scanning and photogrammetry and their combined use for digital recording of cultural heritage," Int. Arch. Photogramm., 2004.

[4] P. Grussenmeyer, T. Landes, T. Voegtle, and K. Ringle, "Comparison methods of terrestrial laser scanning, photogrammetry and tacheometry data for recording of cultural heritage buildings," Int. Arch. Photogramm. Remote Sens. Spat. Inf. Sci., vol. 37 (B5), pp. 213-218, 2008.

[5] S. Martínez, J. Ortiz, M. L. Gil, and M. T. Rego, "Recording Complex Structures Using Close Range Photogrammetry: The Cathedral of Santiago De Compostela," Photogramm. Rec., vol. 28, no. 144, pp. 375-395, Dec. 2013, doi: 10.1111/phor.12040.

[6] F. Fassi, C. Achille, and L. Fregonese, "Surveying and modelling the main spire of Milan Cathedral using multiple data sources," Photogramm. Rec., vol. 26, no. 136, pp. 462487, Dec. 2011.

[7] J. Alanyà, Sant Miquel de Batea. La catedral de Terra Alta. Tortosa: Imprenta Querol, SL, 2019.

[8] A. Costa-Jover, J. Lluis i Ginovart, S. Coll-Pla, and M. López Piquer, "Using the terrestrial laser scanner and simple methodologies for geometrically assessing complex masonry vaults," J. Cult. Herit., 2018.

[9] E. Quagliarini, P. Clini, and M. Ripanti, "Fast, low cost and safe methodology for the assessment of the state of conservation of historical buildings from 3D laser scanning: The case study of Santa Maria in Portonovo (Italy)," J. Cult. Herit., 2016

[10] E. Bonali, A. Pesci, G. Casula, and E. Boschi, "Deformation of Ancient Buildings inferred by Terrestrial Laser Scanning methodology: the Cantalovo church case study (Northern Italy)*," Archaeometry, vol. 56, no. 4, pp. 703-716, Aug. 2014. 